Jurnal Intelektualita: Keislaman, Sosial, dan Sains

Vol. 9 No. 2 (2020)

DOI: https://doi.org/10.19109/intelektualita.v9i2.6798

Copyright @ 2020 Fitri Dwiratnasari, Achmad Junaedi, Lilis Karyawati

\title{
Pengaruh Komunikasi Keluarga terhadap Prestasi Belajar Siswa pada Mata Pelajaran Pendidikan Agama Islam di SMPN 7 Karawang
}

\author{
Fitri Dwiratnasari ${ }^{1 *}$, Achmad Junaedi ${ }^{1}$, Lilis Karyawati ${ }^{1}$ \\ ${ }^{2}$ Universitas Singaperbangsa Karawang, Indonesia
}

\begin{abstract}
Abstrak: Tujuan penelitian ini adalah ingin mengetahui komunikasi keluarga, prestasi belajar siswa, serta pengaruh antara komunikasi keluarga terhadap prestasi belajar PAI. Metode yang digunakan yaitu metode kuantitatif deskriptif. Data dikumpulkan dengan menggunakan angket, langkahlangkah analisis statistik menggunakan uji parsial, uji normalitas, uji korelasi uji hipotesis dan uji pengaruh. Hasil penelitian menunjukan bahwa komunikasi keluarga berpengaruh terhadap prestasi belajar siswa pada mata pelajaran PAI. hal ini terbukti dari rata- rata nilai angket (Variabel X) serta nilai Raport (Variabel Y). Nilai rata-rata Angket sebesar 3.46 dan nilai rata-rata Raport sebesar 81.4. Jadi Pengaruh Komunikasi Keluarga terhadap Prestasi Belajar Siswa pada mata pelajaran PAI diperoleh nilai perhitungan dari koofisien korelasi sebesar 0.36 dapat dikategorikan korelasi tinggi, krena berada diantara $0.61 \mathrm{~s} / \mathrm{d} 0.80$ dengan derajat pengaruhnya $22 \%$. Artinya masih terdapat $78 \%$ faktor lain yang bisa memmpengaruhi atau memberikan kontribusi kepada Prestasi Belajar Siswa pada Mata Pelajaran PAI.
\end{abstract}

Kata Kunci: pengaruh, komunikasi keluarga, prestasi belajar

\begin{abstract}
The purpose of this study was to determine family communication, student achievement, and the effect of family communication on learning achievement of Islamic Education. The method used is descriptive quantitative method. Data were collected using a questionnaire, statistical analysis steps using a partial test, normality test, correlation test, hypothesis test and influence test. The results showed that family communication had an effect on student achievement in Islamic Education subjects. This is evident from the average value of the questionnaire (Variable X) and the value of report cards (Variable Y). the average value of the questionnaire was 3.46 and the average value of the report cards was 81.4. So the effect of family communication on student learning achievement in the PAI subject, the calculated value of the correlation coefficient of 0.36 can be categorized as high correlation, because it is between $0.61 \mathrm{~s} / \mathrm{d} 0.80$ with a degree of influence of $22 \%$. This means that there are still $78 \%$ of other factors that can influence or contribute to Student Achievement in Islamic Education Subjects.
\end{abstract}

Keywords: influence, family communication, learning achievement

\section{Pendahuluan}

Pengaruh lingkungan keluarga sangat besar terhadap anak. Lingkungan keluarga merupakan tempat dimana seorang anak berinteraksi untuk pertama kalinya. Orang tua adalah sebagai pendidik pertama dan utama di lingkungan keluarga. Lingkungan keluarga juga merupakan tempat seorang anak menerima ajaran-ajaran dan berbagai didikan dari orang tuanya, sehingga secara tidak langsung akan mempengaruhi segala tindakan anaknya.

\footnotetext{
* Corresponding Author: Mohamad Fahri (absolutefahri@gmail.com). Kementerian Agama Jakarta, Indonesia
} 
Kebiasaan dan kepribadian anak pun tergantung bagaimana cara orang tuanya mendidik. Beberapa teori pendidikan yang kita kenal, misalnya teori empirisme menyebutkan bahwa anak lahir seperti kertas putih (tabularasa), yang bisa ditulis apa saja oleh orang dewasa (orang tua, orang-orang dewasa lain di lingkungannya) (Kurniawan, 2017).

Keluarga sebagai lingkungan pertama sangat berpengaruh dalam membentuk pola kepribadian anak. Anak pertama kali berkenalan dengan nilai dan norma di dalam keluarga. Pendidikan keluarga memberikan pengetahuan dan keterampilan dasar, agama dan kepercayaan, nilai-nilai moral, norma sosial dan pandangan hidup yang diperlukan anak (Helmawati, 2014). Pendidikan bisa didapatkan melalui lingkungan keluarga, sekolah dan masyarakat. Sekolah menjadi lembaga pendidikan formal sebagai tempat untuk mendidik dan membimbing anak-anak kea rah yang lebih baik. Orang tua menyerahkan anaknya kesekolah agar sekolah memberikan pendidikan yang baik. Namun sekolah berharap agar orang tua memberikan dukungan terhadap usaha sekolah dalam memberikan pendidikan yang baik bagi anak-anaknya. Pendidikan yang baik ini akan terwujud apabila keluarga dalam hal ini adalah orang tua peduli dengan membantu, memotivasi, membimbing dan mengarahkan anak agar lebih semangat dan bersungguh-sungguh dalam belajar.

Di Indonesia pada saat ini masih sering kali dijumpai siswa yang bolos pada jam-jam masih berlangsung, dan bahkan masih ada yang ikut tauran. Dalam hal ini banyak orang tua yang tidak memiliki waktu yangcukup untuk membimbing dan mengawasi anak dalam belajar. Orang tua sibuk bekerja untuk memenuhi kebutuhan hidup. Selain itu, banyak orang tua yang kurang mengawasi pergaulan dan kegiatan anak di luar rumah. Kurangnya perhatian orang tua dengan pihak sekolah, kepada wali kelas maupun Guru BK, orang tua datang ke sekolah hanya satu tahun sekali saat mengambil rapot saja.

Komunikasi dalam keluarga merupakan suatu hal yang sangat penting. Pendidikan yang dilakukan di lingkungan keluarga oleh orang tua kepada anak dilakukan melalui kegiatan komunikasi anatara orang tua dan anak. Usaha untuk memudahkan dalam mendidik anak dapat diawali dengan membangun komunikasi yang harmonis dengan anak. Keberhasilan membangun komunikasi keluarga yang harmonis dalam rangka mendidik anak cerdas tidak terlepas dari perhatian orang tua dalam memanfaatkan sejumlah etika komunikasi. Komunikasi yang berkualitas juga diperlukan dalam mendidik anak. Orang tua perlu meluangkan waktu untuk berkomunikasi dengan anak dan harus pandai mengarahkan komunikasi ini agar dapat memberikan bimbingan dan pengarahan yang tepat (Djamarah, 2004).

Orang tua yang menginginkan anaknya belajar dengan sungguh- sungguh dan berprestasi disekolah tanpa didukung dengan sifat mendidik yang benar dan komunikasi yang kurang baik, maka perkembangan anak di sekolah akan terabaikan, seperti anak tidak memiliki keinginan dan ketertarikan belajar yang tinggi. lingkungan rumah khususnya komunikasi orang tua dengan anak merupakan salah satu factor non kognitif yang dapat mempengaruhi kebiasaan belajar (Rahmawati, 2011).

Untuk mencapai prestasi belajar siswa sebagaimana diharapkan, maka perlu diperhatikan beberapa faktor yang 
mempengaruhi prestasi belajar antara lain: faktor yang terdapat dalam diri siswa (faktor intern) seperti intelegensi, minat, bakat, motivasi, dan sikap dan faktor yang terdapat diluar diri siswa (faktor ekstern) seperti guru, orang tua atau keluarga, kurikulum, saranaprasarana sekolah serta kondisi kelas.

Berdasarkan uraian tersebut dapat dipahami bahwa salah satu faktor yang mempengaruhi prestasi belajar siswa adalah faktor keluarga. Perhatian dan bimbingan orang tua sangat diperlukan sebagai penguat dalam proses pembelajaran (Slameto, 2010). Komunikasi orang tua mempunyai peran sangat penting dalam membimbing anak- anaknya. Orang tua harus pandai mengarahkan komunikasi agar bisa memberikan bimbingan dan pengarahan belajar pada anak yang tepat. Persoalan yang muncul adalah komunikasi orang tua dengan anaknya banyak mengalami hambatan atau bisa dikatakan komunikasi orang tua dengan peserta didik kurang baik. Orang tua yang seharusnya memberikan perhatian kepada anaknya seperti memberikan semangat, dukungan dan nasehat kepada anaknya tentang pendidikan disekolahnya tetapi orang tua hanya memberikan kebutuhan untuk membiayai dan memberikan keperluan untuk anaknya. Kadangkadang orang tua bertemu anaknya setiap hari tetapi tanpa ada komunikasi mengenai kegiatan belajar anak di sekolah sehingga anak menjadi malas dan tidak mempunyai ketertarikan belajar.

\section{Metode Penelitian}

Penelitian ini berbentuk penelitian kuantitatif, yang terdapat dua macam variabel yaitu variabel bebas komunikasi keluarga dan variabel terikat Prestasi Belajar Siswa. Dalam mengumpulkan data peneliti menggunakan dua cara yaitu dengan kuisioner (angket) dan dokumentasi. Ada dua sumber dalam penelitian ini sumber utama (primer) dan sumber pendukung (sekunder). Yang menjadi sumber utama penelitian ini yaitu kuisioner (angket) yang di isi oleh responden dan yang menjadi sumber pendukung berupa foto maupun dokumen tertulis. Peneliti dalam menganalisis data menggunakan beberapa teknik analisis data, analisis data dengan uji validitas, kemudian uji realibilitas, uji normalitas, uji homogenitas, uji $\mathrm{R}$, uji $\mathrm{T}$, dan uji determinasi. Sebelum melakukan pengelohan data peneliti terlebih dahulu mempersiapkan kisi-kisi instrument penelitian.

\section{Hasil Penelitian dan Pembahasan}

Terdapat perngaruh pelaksanaan Komunikasi Keluarga terhadap Prestasi Belajar siswa dalam mempelajari bidang studi Pendidikan Agama Islam. Hal ini dibuktikan melalui analisis koofisien korelasi sebesar 0.63 dapat dikategorikan korelasi tinggi, karena berada diantara $0.61 \mathrm{~s} / \mathrm{d} 0.80$ dengan derajat pengaruhnya $22 \%$. Artinya masih terdapat $78 \%$ merupakan faktor lain. Kemudian hipotesis yang penulis ajukan ternyata Diterima. Artinya Komunikasi Keluarga terhadap Prestasi Belajar PAI berpengaruh, dan masih banyak faktor lain yang mempengaruhi Prestasi Belajar Siswa.

\section{Kesimpulan}

Hasil penelitian menunjukan bahwa adanya pengaruh antara komunikasi keluarga terhadap prestasi belajar siswa. Oleh karena itu diharapkan kepada orang tua harus menjaga komunikasi antara anggota keluarga, karena kondisi komunikasi mempengaruhi prestasi belajar anak disekolah khususnya pada mata pelajara PAI. Hasil pengolahan data pelaksanaan Komunikasi Keluarga di SMPN 7 Karawang 
diperoleh dengan nilai rata-rata 3.46 termasuk kategori sedang karena berada pada interval 2.5 - 3.5. Dari hasil pengelolaan data realitas Prestasi Belajar PAI diperoleh dengan nilai ratarata 81.4 termasuk kategori sedang.

\section{Daftar Pustaka}

Djamarah, Syaiful Bahri. 2004. Pola Komunikasi Orang Tua dan Anak dalam Keluarga: Sebuah Perspektif Pendidikan Islam. Jakarta: PT Rineka Cipta.

Helmawati. 2014. Pendidikan Keluarga Teoritis dan Praktis. Bandung: Remaja Rosdakarya.

Kurniawan, Syamsul. 2017. Pendidikan Karakter: Konsepsi \& Implementasinya secara Terpadu di Lingkungan Keluarga, Sekolah, Perguruan Tinggi dan Masyarakat. Jakarta: Ar-Ruzz Media.

Padjrin, P. (2016). Pola Asuh Anak dalam Perspektif Pendidikan Islam. Jurnal Intelektualita: KeIslaman, Sosial Dan Sains, 5(1), $\quad 1 \quad-14$. https://doi.org/https://doi.org/10.19109/intele ktualita.v5i1.720

Zaini, H., Hadi, A., Sofyan, F. A., \& Hamzah, A. (2021). Covid-19 and Islamic Education in School: Searching for Alternative Learning Media. Webology, 18(1).

Rahmawati, Nurul dan Tri Esti Budiningsih. 2011. "Hubungan antara Kualitas Komunikasi Anak dan Orang Tua dengan Kebiasaan Belajar Siswa SMPN 13 Semarang Tahun Ajaran 2011-2012". Jurnal Psikologi Ilmiah. Vol. 4 No.1 Semarang: Universitas Negeri Semarang.

Slameto. 2010. Belajar dan Faktor-faktor yang mempengaruhinya. Jakarta: Rineka Cipta 